\title{
The influence of the casting process on the internal structure and physical properties of hemp-lime
}

\author{
Joseph Williams (iD) Mike Lawrence $\cdot$ Pete Walker
}

Received: 27 September 2016/Accepted: 28 November 2016/Published online: 9 December 2016

(C) The Author(s) 2016. This article is published with open access at Springerlink.com

\begin{abstract}
Bio-aggregate composites such as hemplime offer a more sustainable alternative to traditional walling infill material. Hemp-lime, whether in situ or prefabricated, is generally either cast or sprayed, which results in a directionally dependent, typically layered, physical structure. This paper considers the impact of compaction and layering on the directional thermal conductivity, compressive strength and internal structure of the material through use of a novel image analysis method. The results presented indicate that production variables have a significant, and crucially, directionally dependent impact on the thermal and mechanical properties of cast hemp-lime.
\end{abstract}

Keywords Hemp-lime $\cdot$ Bio-aggregate $\cdot$ Image analysis - Compressive strength - Thermal conductivity $\cdot$ Directional modeling

\section{Introduction}

Hemp-lime is a bio-aggregate composite material produced by combining the chopped woody core of the hemp plant (shiv), a lime-based binder and water.

J. Williams $(\varangle) \cdot$ M. Lawrence $\cdot$ P. Walker BRE Centre for Innovative Construction Materials, Department of Architecture and Civil Engineering, University of Bath, Bath BA2 7AY, UK

e-mail: J.P.Williams@bath.ac.uk
The resulting mixture can be cast or sprayed into place and cures to form a rigid but highly voided structure. The large proportion of bio-sourced material means that hemp-lime is a net absorber of carbon dioxide that is essentially sustainable to produce [1-3]. The multi scaled porous structure within hemp-lime produces a high thermal resistivity alongside a high thermal storage capacity and moisture buffering properties, making it a desirable infill insulation material for use in building envelopes [4-7].

The most common method used to manufacture hemp-lime is to mix the components into a wet mix that is cast within formwork or block moulds. The process of casting is usually conducted in layers that are individually placed by tamping. The depth of layers, the degree of compaction and the direction of compaction with respect to the direction of thermal and mechanical loading are all variables within this process. The distribution of density within cast material is known to be dependent on depth within a single layer and globally a function of compaction $[8,9]$; it is also known that the casting process produces an orientated internal structure [10]. Taken together these variables will in part determine the internal topology of the material and thus have an influence on the physical properties.

The effect of compaction of hemp-lime on the mechanical and thermal properties has been studied previously. Nguyen et al. [8,9] found that static load compaction of fresh hemp-lime during casting can 
improve the peak compressive strength and stiffness of the material; the thermal conductivity was also seen to increase but to a lesser extent. The results are attributed to a reduction of inter particle voids that would reduce the volume fraction of thermally resistive air and increase the volume fraction of structural binder. It is proposed elsewhere [11-16] and widely accepted that compressive strength and thermal conductivity of hemp-lime follows an approximate linear relation to density for this reason.

The density distribution through specimens of sprayed hemp-lime has been assessed previously and found to vary with depth [15]. In addition it has been observed elsewhere that cylinders of hemp lime cast in three layers will tend to fail in compression in the top third [17], suggesting of a lower density of material in this area. It is known from the study of other aggregate material that self-weight and boundary friction will impact density profile of a compacted layer. As these are both a result of the layer size then it is appropriate that for cast material, the layer size may influence the density distribution of the composite and impact on the physical properties. To the authors' knowledge, no preceding study exists that directly assesses how the size of layers used to cast hemp-lime influences the physical properties.

The aggregate used for hemp-lime comes from the stem of the plant and is therefore generally of an elongated form. The application of any compaction has been shown to produce a preferential orientation of the particles towards stratified planes perpendicular to the compacting force [10] that is widely considered to produce observed anisotropic behaviour [8, 18-21]. The compressive strength, compressive stiffness and failure mode of compacted hemp lime have been shown to depend on whether testing is conducted parallel or perpendicular to the compaction force [21] as has thermal conductivity $[8,20]$.

This paper considers how the variables of layer size and compaction affect the directional compressive behaviour and thermal conductivity of hemp-lime. Results are presented from uniaxial heat flow test and uniaxial compressive test for five permutations of cast material in two orientations (perpendicular and parallel with respect to casting). Additional information about the internal structure, obtained using a recently developed method of image analysis, is also presented.

\section{Methodology}

\subsection{Specimen production}

A single mixture of hemp-lime was used to investigate the influence of the internal structure on its properties, with the method of specimen casting the primary variable. The hemp shiv used was produced in France and the bulk properties and particle size distribution are reported in Table 1 and Fig. 1 respectively. The binder used was a commercially available formulated binder for use with hemp, containing mainly a high surface area natural hydraulic lime with the addition of pozzolanic additives. The ratio of binder, hemp and water used throughout the study was 2.25:1.0:3.0 (by mass), which is representative of the ratios widely used for walling applications [22, 23].

Mixing of the constituent materials was carried out in a revolving pan mixer. The binder and water were first combined to form a uniform slurry prior to the addition of the hemp shiv. Subsequent mixing was then conducted until a uniform mixture was achieved, paused occasionally to break up any clumps forming by hand. Pre-determined quantities of mixture were weighed out into oiled moulds and tamped to height successively to build up each specimen in the required number of layers. The specimens were left uncovered and transferred to a conditioning room at $20{ }^{\circ} \mathrm{C}$ and $70 \%$ relative humidity with the moulds being removed after six days.

Specimens were produced using a range of three layer sizes: 25,50 and $150 \mathrm{~mm}$; and three compaction levels: 30,45 and $60 \%$ volumetric decrease from the uncompact state. Two sets, one to be tested parallel to compaction and one to be tested perpendicular to compaction, were produced for each variant of layer size and compaction level; the full range of permutations considered is detailed in Table 2 and diagrammatically explained in Fig. 2. For each of these permutations, three $150 \mathrm{~mm}$ cube specimens were produced for compressive testing with a further three produced for assessment of the internal structure. In addition a single $400 \mathrm{~mm}$ by $400 \mathrm{~mm}$ by $50 \mathrm{~mm}$ specimen was produced for thermal conductivity testing for all permutations except variant 6 where a $150 \mathrm{~mm}$ layer would exceed the required $50 \mathrm{~mm}$ specimen thickness. 
Table 1 Hemp shiv properties

\begin{tabular}{llllll}
\hline $\begin{array}{l}\text { Country } \\
\text { of origin }\end{array}$ & $\begin{array}{l}\text { Bulk density } \\
\left(\mathrm{kg} \mathrm{m}^{-3}\right)\end{array}$ & $\begin{array}{l}\text { Mean particle } \\
\text { length }(\mathrm{mm})\end{array}$ & $\begin{array}{l}\text { Length standard } \\
\text { deviation }(\mathrm{mm})\end{array}$ & $\begin{array}{l}\text { Mean particle } \\
\text { width }(\mathrm{mm})\end{array}$ & $\begin{array}{l}\text { Width standard } \\
\text { deviation }(\mathrm{mm})\end{array}$ \\
\hline France & 122 & 3.34 & 3.51 & 1.06 & 0.987 \\
\hline
\end{tabular}

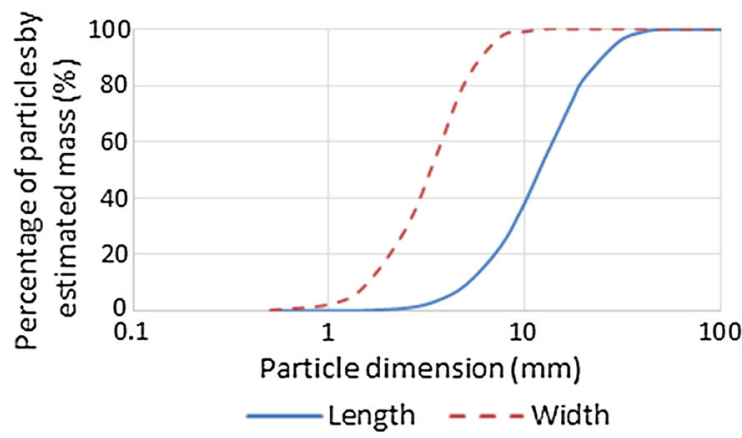

Fig. 1 Particle size distribution, length and width, from 2D image analysis

\subsection{Experimental procedure}

The methods and specimen ages from casting were chosen based on combination of the British Standards for compressive strength testing of concrete and insulation products $[24,25]$, as well as preceding studies on hemp-lime $[8,11,15,17]$. All specimens were removed from the temperature and humidity controlled curing room and tested at 28 days after casting. Specimen masses and dimensions were measured to obtain 28 day densities as well as geometric parameters required for the calculation of stress and strain. Compressive tests were conducted using an Instron $50 \mathrm{KN}$ testing rig at a controlled displacement of $3 \mathrm{~mm} / \mathrm{min}$; the inbuilt instrumentation was used to both record load and platen displacement at a resolution of one data point per $0.1 \mathrm{~s}$.

Thermal conductivity measurements were conducted on the $50 \mathrm{~mm} \times 400 \mathrm{~mm} \times 400 \mathrm{~mm}$ specimens following oven drying for $48 \mathrm{~h}$ at $105^{\circ}$. Mass and dimensions were recorded for all specimens to determine density and for use in calculation of thermal conductivity. The thermal conductivity tests were undertaken using a Fox 600 heat flow meter with a temperature gradient of 10 to $30{ }^{\circ} \mathrm{C}$. Prior to testing the specimens were wrapped with a single layer of clear shrink wrap food packing material in order to both protect the instrument and prevent moisture loss from the specimens during testing.

Assessment of each internal specimen structure was conducted using an original method developed by the authors [10]. In brief it comprises cutting six slices from each specimen using a band saw with the cuts made in the perpendicular plane to the direction of thermal and mechanical loading. The cut faces of each slice were then cast within a low viscosity colored

Table 2 The design permutations of hemp-lime specimens produced

\begin{tabular}{llllll}
\hline $\begin{array}{l}\text { Variant } \\
\text { number }\end{array}$ & $\begin{array}{l}\text { Direction of testing in } \\
\text { relation to casting }\end{array}$ & $\begin{array}{l}\text { Compaction (\%vol reduction } \\
\text { of uncompact) }\end{array}$ & $\begin{array}{l}\text { Size of layers } \\
(\mathrm{mm})\end{array}$ & $\begin{array}{l}\text { Green density } \\
\left(\mathrm{kg} \mathrm{m}^{-3}\right)\end{array}$ & $\begin{array}{l}\text { Ave } 28 \text { day density } \\
\left.(\mathrm{kg} \mathrm{m})^{-3}\right)\end{array}$ \\
\hline 1 & Parallel & 45 & 150 & 649 & 423 \\
2 & Parallel & 30 & 50 & 577 & 374 \\
3 & Parallel & 45 & 50 & 649 & 412 \\
4 & Parallel & 60 & 50 & 721 & 462 \\
5 & Parallel & 45 & 25 & 649 & 406 \\
6 & Perpendicular & 45 & 150 & 649 & 408 \\
7 & Perpendicular & 30 & 50 & 577 & 355 \\
8 & Perpendicular & 45 & 50 & 649 & 399 \\
9 & Perpendicular & 60 & 50 & 721 & 450 \\
10 & Perpendicular & 45 & 25 & 649 & 411 \\
\hline
\end{tabular}




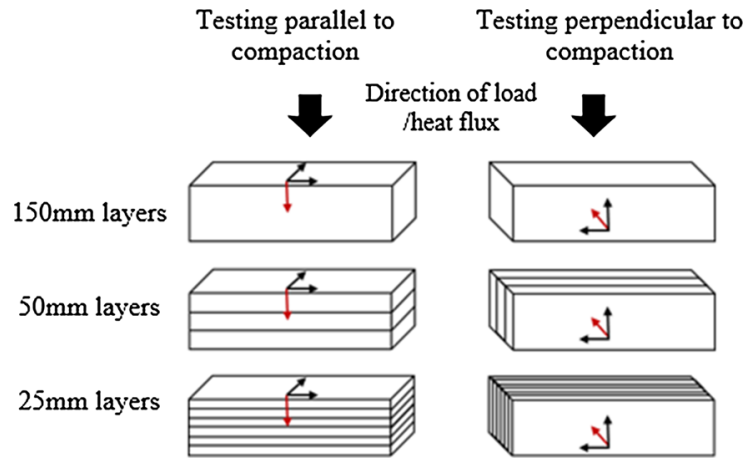

Fig. 2 Layering and testing direction arrangements for parallel and perpendicular loading with direction of compaction and preferred plane of orientation of particles indicated by the red and black axis respectively. (Color figure online)

resin, used to highlight the voids within the material, and sanded to reveal a section through the material; the prepared surfaces were 'imaged' with a flatbed scanner at a resolution of 1200 dpi. To enhance the contrast of the images produced, a red pigment was added to the slaked binder used in the production of the specimens to enable easier computer recognition of the differing parts of the image: voids (blue resin) binder (red) and hemp shiv (natural yellow).

Analysis of the images was carried out using ImageJ primarily using the measure and partial analysis tools. Prior to analysis the images were smoothed using a median filter to remove noise and then a threshold analysis was undertaken to identify a single constituent and binaries the image. Following this the binary image was further cleaned by use of an opening algorithm to help segregate touching particles and finally a partial analysis was conducted to identify and measure the discreet binary objects (shiv particles) within each image. The orientation of each particle within the image plane was assessed by means of an ellipse fitting process, as described in [10] and the results were combined into frequency analysis of the whole population to give an assessment of global orientation within the plane.

\section{Results}

\subsection{Density}

The 28 day average density of the different variations of material is given in Table 2 while the dry densities obtained after $48 \mathrm{~h}$ oven drying at $105{ }^{\circ} \mathrm{C}$ are given in Table 3. From table two it is apparent that the density at 28 days varies with orientation of casting as well as compaction but not layer thickness; the parallel compaction direction is found to be on average $2.6 \%$ higher than the parallel direction. From the dry densities, Table 3 again the dry densities are found to be higher in the parallel direction however in this case the average increase is only $1.5 \%$ and of comparable magnitude to the average variation found between similar specimens of $1.0 \%$. It is suggested therefore that the casting orientation has bearing on the drying hysterics of the material and thus the 28 day density but negligible impact on the dry density of the material, considered to be solely a result of the compaction where the constituents are kept constant.

\subsection{Compressive behaviour}

The average stress-strain graphs for three specimens tested parallel (variant 3) and perpendicular (variant 8 ), with the median layer size and compaction, are shown in Fig. 3. As observed previously the failure mode exhibited when loaded parallel to the casting compaction direction was different to that when loaded perpendicular. A difficulty therefore arises in selecting a definition of compressive strength that can be compare performance in both directions. This is made harder still by the lack of a definable peak stress observed in parallel loading of cube specimens, but rather strain hardening, and a variable initial period of material settling, Fig. 3.

As insulation materials typically have much lower stiffness compared to structural materials, the compressive resistance of insulation materials, such as rigid foam, is commonly defined as the stress attained at a given strain level [24]. A similar approach has also previously been adopted in the study of bio-aggregate composites [26-28]. As the strain level that defines resistance is somewhat arbitrary, combined with the variable initial settling period for hemp-lime, an alternative approach was proposed for parallel loaded material by Tronet et al. based on a model developed for FRP-confined concretes [16]. This approach uses a repeatable method for the calculation of a yield stress that is both independent of initial displacement (settling) and compatible with prolonged strain hardening. However, whilst this approach is a development from that that of preceding studies, it is not applicable 
Table 3 Volumetric proportion of air obtained by 2D image analysis of hemp-lime at different compaction levels

\begin{tabular}{llllll}
\hline $\begin{array}{l}\text { Variant } \\
\text { number }\end{array}$ & $\begin{array}{l}\text { Direction of testing in } \\
\text { relation to casting }\end{array}$ & $\begin{array}{l}\text { Compaction (\%vol } \\
\text { reduction of uncompact) }\end{array}$ & $\begin{array}{l}\text { Size of } \\
\text { layers }(\mathrm{mm})\end{array}$ & $\begin{array}{l}\text { Volume of air } \\
(\% \text { macroscopic level) }\end{array}$ & $\begin{array}{l}\text { Dry density } \\
\left(\mathrm{kg} \mathrm{m}^{-3}\right)\end{array}$ \\
\hline 1 & Parallel & 45 & 150 & 30.8 & 345 \\
2 & Parallel & 30 & 50 & 40.7 & 319 \\
3 & Parallel & 45 & 50 & 32.7 & 338 \\
4 & Parallel & 60 & 50 & 23.5 & 379 \\
5 & Parallel & 45 & 25 & 31.6 & 338 \\
6 & Perpendicular & 45 & 150 & 35.8 & 336 \\
7 & Perpendicular & 30 & 50 & 41.7 & 304 \\
8 & Perpendicular & 45 & 50 & 35.6 & 337 \\
9 & Perpendicular & 60 & 50 & 23.8 & 372 \\
10 & Perpendicular & 45 & 25 & 31.6 & 346 \\
\hline
\end{tabular}

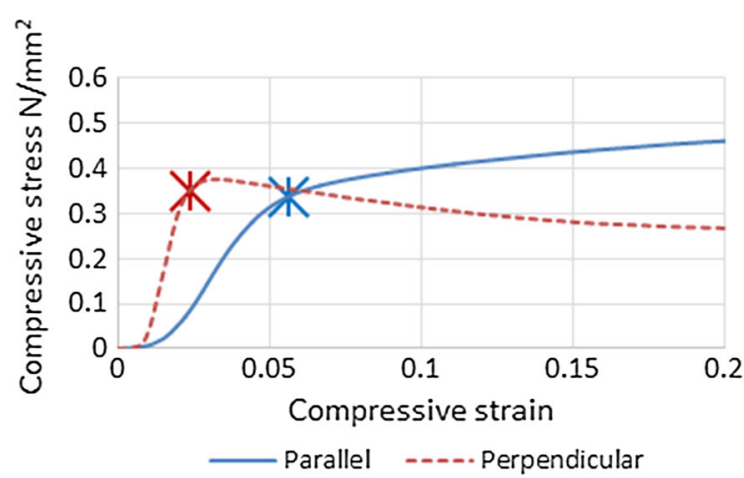

Fig. 3 The stress strain relationship for parallel and perpendicular loaded hemp lime cube specimens with the rupture stress indicated

for material loaded in the perpendicular direction that do exhibit a peak stress and no strain hardening post yielding and so was not applicable to this study.

An alternative parameter is proposed in this study to compare hemp-lime material performance in both loading orientations. The composite rupture stress has been defined in this study thus: the stress at the strain where the tangent Young's Modulus of the material, taken from a moving sample of twenty consecutive data points, falls to $25 \%$ of its peak value. While the selection of the proportion is in itself arbitrary, the threshold strain value is determined by the material's behaviour. The proposed approach accounts for both the initial low stiffness (settling) and the different apparent stiffness of the hemp-lime in each direction, while being insensitive to post yielding behaviour.
The effect of compaction and layer size on compressive rupture stress in both the parallel and perpendicular directions is shown in Fig. 4. The compressive rupture stress of hemp-lime increases with increasing casting compaction effort in both the perpendicular and parallel loaded directions, Fig. 4 (left). For a $30 \%$ increase in compaction the rupture stress increased by 200 and $175 \%$ in the perpendicular and parallel directions respectively. The average coefficient of variance from the results represented in Fig. 4 (left) was found to be $7.0 \%$, indicating that while the natural variance in these materials is high, the increase from compaction in both cases is a significant result.

The compressive rupture stress of hemp-lime is generally independent of casting layer thickness within the range of 150to $25 \mathrm{~mm}$, in both the parallel and perpendicular directions with respect to casting [Fig. 4 (right)]. There is a small apparent increase in compressive rupture strength in the perpendicular direction of 17 and $30 \%$ respectively for casting in 25 and $150 \mathrm{~mm}$ layers compared to $50 \mathrm{~mm}$. While the average coefficient of variance for these results, $6.6 \%$, indicates these increases may be significant, it is noted that they are of significantly lower magnitude that those observed in altering compaction, and have come from a relatively small sample size.

\subsection{Thermal conductivity}

The thermal conductivity results for the hemp-lime materials considered are presented in Fig. 5. On 
Fig. 4 The parallel and perpendicular compressive rupture stress of hemp-lime at different compaction levels (left) and different layer thicknesses (right)

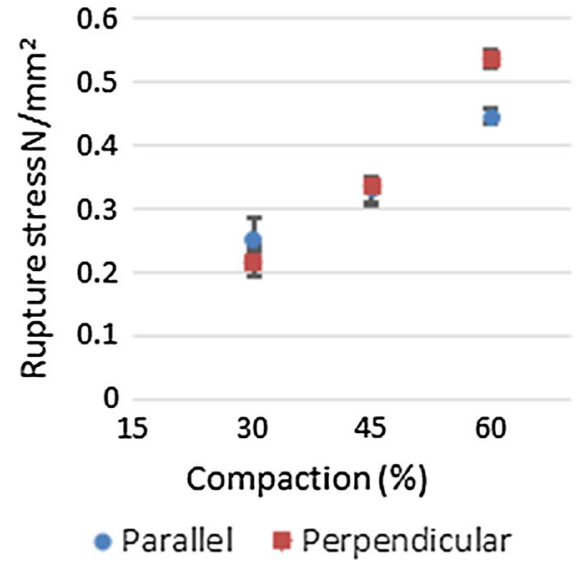

average the perpendicularly tested specimens exhibited a $16 \%$ higher thermal conductivity than the parallel tested specimens. While this is lower than the results reported by Pierre [20], who found a 33\% directional difference in thermal conductivity, it is in line with the results of several others [29, 30]. It is observed from Fig. 5 (left) that compaction has a strong positive correlation with thermal conductivity. There is no evidence of a correlation between layer thickness and thermal conductivity in the perpendicular direction and the omission of a result for a $150 \mathrm{~mm}$ thick layer means no conclusive statements can be drawn in the parallel direction.

\subsection{Internal structure}

The results for the frequency analysis of particle orientation are presented in Fig. 6 and the volumetric proportions of air voids obtained and the 28 day density presented in Table 3 . A clear difference is observed in the frequency diagrams between the perpendicular and parallel orientations, which is indicative of an anisotropic internal structure, consistent with previous results presented previously by the authors [10].

Neither compaction nor layer thickness affect the particle distribution in the parallel direction, which remained consistent in all cases (Fig. 6). The shape of the graph in this instance suggests an even and thus random distribution of particles as would be expected in planes perpendicular to the compacting force. The slightly higher frequencies at the extremes, $0^{\circ}$ and $90^{\circ}$, are believed to be a result of the mould edges.

In the perpendicular direction there is again consistency in the distributions across compaction and layer thickness indicating a minimal impact. Variant 7, the lowest compaction level, appears to have the flattest graph and thus lowest degree of orientation. A relationship between compaction and degree of orientation is, however, not observed as the
Fig. 5 The parallel and perpendicular thermal conductivity of dry hemplime at different compaction levels (left) and different layer thicknesses (right)
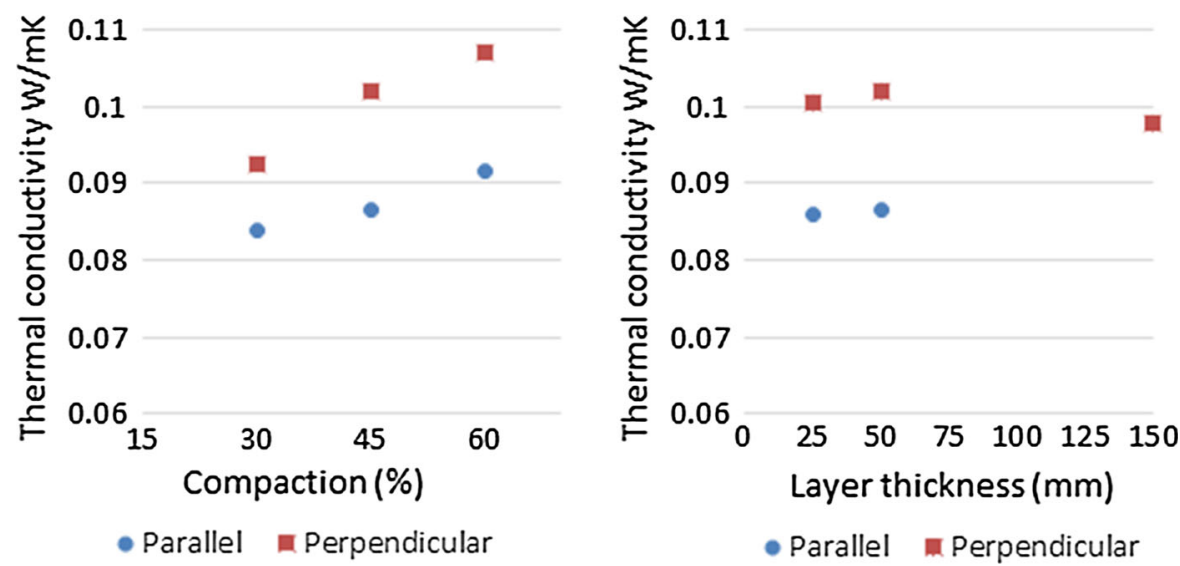
Fig. 6 The parallel and perpendicular particle orientation frequency distributions obtained by $2 \mathrm{D}$ image analysis of hemplime at different compaction levels (left) and different layer thicknesses (right)

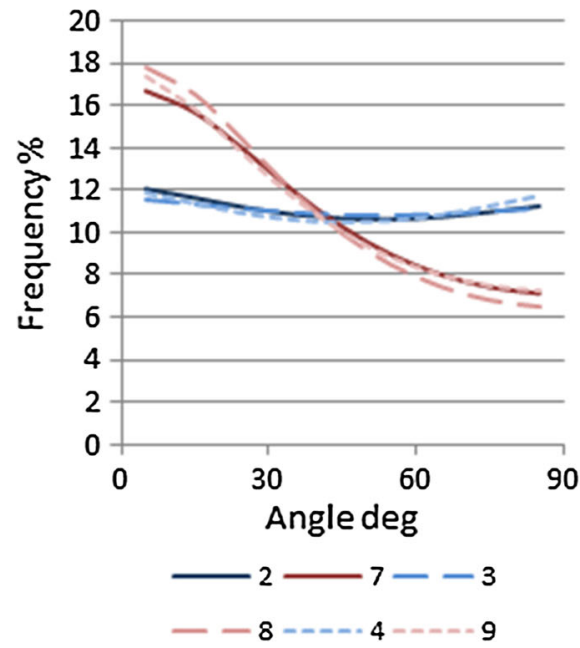

most compact (variant 9), is observed to have a flatter graph than the median compaction (variant 8). From Fig. 6 (right) the variant with the largest layer sizing (variant 6) appears to have a flatter graph than the similar variants of smaller layer sizes. Variations in all cases are however small and comparable to the natural variation that is assumed to be exhibited in the perpendicular distributions.

\section{Discussion}

It is evident from the results presented in Fig. 6 that an anisotropy in the particle arrangement of the hemp in hemp-lime composites produces anisotropic thermal and mechanical behavior (Figs. 3, 5). The anisotropic arrangement of the particles is attributed to the casting process, where the application of even the lowest amount of compaction force will tend the particles into stratified planes in the perpendicular direction. As the orientation of the particles is evenly distributed in the other two axes, the result is a material with a bidirectional internal structure and physical properties.

Increasing compaction was found to produce higher compressive rupture stress and thermal conductivity in both orientations, and can be generally attributed to a reduction in the proportion of air voids in the composite, Table 3. The impact of compaction is however not global but instead is observed to have greater bearing in the perpendicular direction; a $30 \%$ increase in compaction resulting in an increase in the rupture stress of $200 \%$ in the perpendicular direction compared to $175 \%$ in the parallel directions. A differing increase of dry density for the two directions was observed, 21.7 and $18.8 \%$ respectively, put down to natural variations in the material and casting that may at least in part account for this.

To ascertain to what extent variation in density might explain the seemingly directionally dependent influence of compaction, the dry density can be plotted against compressive rupture stress, Fig. 7. It can be seen from Fig. 7 that the relation of dry density to compressive rupture strength is not consistent across the two directions. The differing increases of density with compaction observed in the two directions is therefore insufficient alone to account for apparent directionally dependent influence of compaction and a further explanation is needed. A logical reason would be greater compaction producing a greater degree of orientation, however, this is not supported by the image analysis that showed a lower degree of orientation present in the most compact variant. As has been found in similar analysis of other materials [31] it is possible that high compaction could increase the misidentification of touching particles, as single particles, and thus this discrepancy, may be explained by a limitation of the method used.

The layer sizes used in the casting process were not observed to influence either the thermal conductivity or the rupture stress of the material within the range of 25 to $150 \mathrm{~mm}$. It had been thought that the layer size would influence the local distribution of material during casting with smaller layers leading to a more 
Fig. 7 The parallel and perpendicular rupture stress (left) and dry thermal conductivity (right) with respect to density
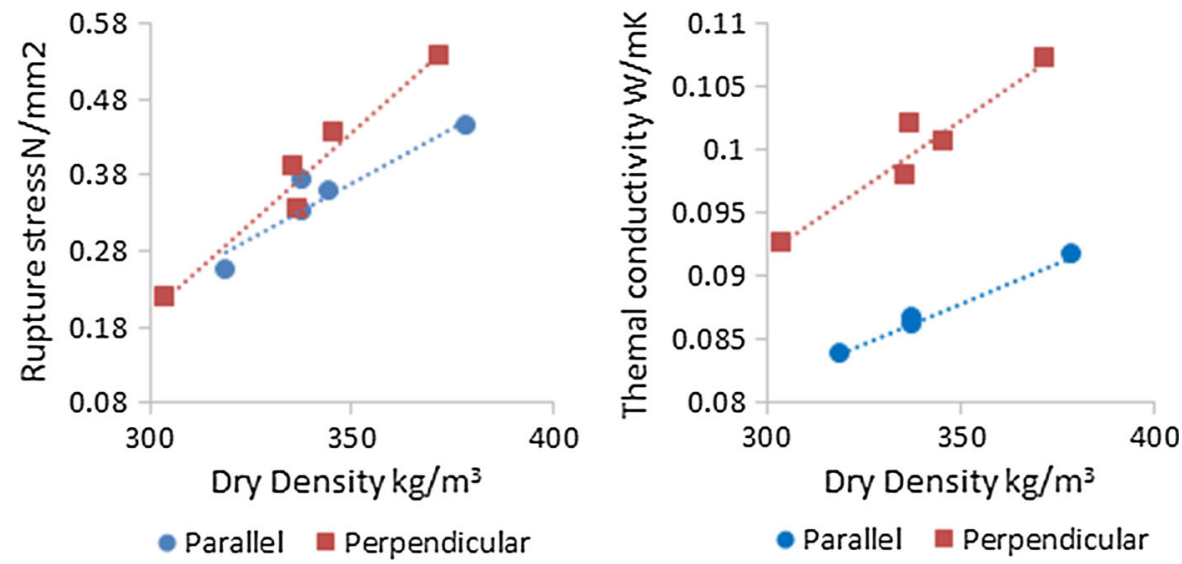

homogenous material. This in turn could reduce possible stress concentrations or thermal bridges through the material thus influencing behaviour. The results indicate that this is not the case for the range of layer sizes considered here, however, the results of others who have plotted density with depth of larger specimens indicate that it may still have bearing at larger layer sizes [8].

A common way to model the thermal conductivity and compressive strength of hemp-lime is as a linear function of dry density [12], as this is both easy to control on site and has been shown to be accurate for most cases. While a linear relationship between density and these properties is a good fit for the results obtained in this study it is also apparent that a single global linear function is not sufficient and different functions are required in the perpendicular and parallel direction respectively, Fig. 7. If it is assumed that the parallel and perpendicular functions are the bounding conditions, then a global model can be produced for thermal and physical loading in any direction by combining them into a weighted function of orientation.

To provide a form for the orientation function a comparison can be made to timber, where the compressive strength is modelled with respect to grain direction by the Hankinsons distribution [32]. As this distribution has already been found by the authors to be an appropriate form for the particle distribution within hemp-lime [10] and thus its internal structure, it is likely that it may also be appropriate for the modelling of thermal conductivity and rupture stress with respect to orientation. By substituting in the linear equations for rupture stress and thermal conductivity as found from the experimental data, Fig. 7, into the Hankinsons form, the following is derived:

Rupture stress

$$
=\frac{(0.0029 \rho-0.66)(0.0048 \rho-1.2)}{(0.0029 \rho-0.66) \sin ^{n} \theta+(0.0048 \rho-1.2) \cos ^{n} \theta},
$$

Thermal conductivity

$$
=\frac{(0.00013 \rho+0.043)(0.00021 \rho+0.028)}{(0.00013 \rho+0.043) \sin ^{n} \theta+(0.00021 \rho+0.028) \cos ^{n} \theta},
$$

where $\rho$ is the dry density of the composite, $\theta$ is the direction of thermal or mechanical loading with respect to the direction of casting compaction and $n$ is a constant that can be derived by fitting to experimental data. The four linear functions fitted to the data in Fig. 7 and used in Eqs. 1 and 2 have R-squared values of $0.878,0.959,0.996$ and 0.920 respectively indicating a good level of fit of these functions and justifying there use in the model.

\section{Conclusions}

This paper considers the influence of the casting process on the thermal and mechanical properties of hemp-lime and applies a newly developed method of image analysis to investigate the role of the internal structure in the manifestation of these properties.

A clear anisotropy in the material's structure is observed through the image analysis for all variations 
considered in this study. This is attributed to the compaction produced in casting causing the elongated particles of hemp to tend towards perpendicular strata. The influence of this on the physical properties of thermal conductivity and compressive behaviour is shown to be profound and so necessitates that further study into bio-aggregate composites accounts for it.

The thickness of the layering used to cast the material was found to have no clear impact on the internal structure or the mechanical properties for the range of layer sizes considered. An initial assumption that a larger layer size would create a less homogenous material was shown not to be the case within the range of this study, however, it is considered likely that this may not apply to larger layer sizes. From a commercial standpoint it can be stated that there is no benefit to using layer sizes smaller than $150 \mathrm{~mm}$ during the manufacture of hemp-lime.

The degree of compaction used in casting was found to influence both the internal structure and in turn the physical properties of the composite. Increasing compaction was found to decrease the proportion of air voids in the material and thus increase both the compressive rupture stress and the dry thermal conductivity; in both cases this was found to be more pronounced in the perpendicular direction. It is considered possible that this is due to a higher level of orientation being produced at higher compaction however this was not confirmed by the image analysis possibly due to a limitation of the method.

The finding that compaction does not have a global impact on the properties of hemp-lime, but rather a directionally dependent one, is of high significance in the modelling of properties and development of the material. A new form of directionally weighted linear model for thermal conductivity and compressive strength is suggested based on a previously established model for timber, although further work is required to ascertain if the Hankinsons form of the weighting equation is more generally applicable.

Acknowledgements This study was funded by the Engineering and Physical Sciences Research Council (grant number EP/L016869/1).

\section{Compliance with ethical standards}

Conflict of interest The authors declare that they have no conflict of interest.
Open Access This article is distributed under the terms of the Creative Commons Attribution 4.0 International License (http:// creativecommons.org/licenses/by/4.0/), which permits unrestricted use, distribution, and reproduction in any medium, provided you give appropriate credit to the original author(s) and the source, provide a link to the Creative Commons license, and indicate if changes were made.

\section{References}

1. Boutin M et al (2005) Analyse du Cycle de Vie de Mur en Béton Chanvre Banché sur Ossature en Bois. INRA, Lille

2. Ip K, Miller A (2012) Life cycle greenhouse gas emissions of hemp-lime wall constructions in the UK. Resour Conserv Recycl 69:1-9

3. Hustache Y, Arnaud L (2008) Synthèse des connaissances sur les bétons et mortiers de chanvre. Construire en Chanvre, Quebec City

4. Evrard A, De Herde A (2010) Hygrothermal performance of lime-hemp wall assemblies. J Building Phys 34(1):5-25

5. Collet F, Pretot S (2014) Experimental highlight of hygrothermal phenomena in hemp concrete wall. Build Environ 82:459-466

6. Lawrence $\mathrm{M}$ et al (2012) Hygrothermal performance of an experimental hemp-lime building. Key Eng Mater 517:413-421

7. Le Tran A et al (2010) Transient hygrothermal behaviour of a hemp concrete building envelope. Energy Build 42(10):1797-1806

8. Nguyen TT et al (2010) Effect of compaction on mechanical and thermal properties of hemp concrete. Eur J Environ Civil Eng 14(5):545-560

9. Nguyen T-T et al (2009) Influence of compactness and hemp hurd characteristics on the mechanical properties of lime and hemp concrete. Eur J Environ Civil Eng 13(9):1039-1050

10. Williams J, Lawrence M, Walker P (2016) A method for the assessment of the internal structure of bio-aggregate concretes. Constr Build Mater 116:45-51

11. Arnaud L et al (2013) Mechanical behavior. bio-aggregatebased building materials. Wiley, New York, pp 153-178

12. Cerezo V (2005) Propriétés mécaniques, thermiques et acoustiques d'un matériau à base de particules végétales: approche expérimentale et modélisation théorique. L'Institut National des Sciences Appliquées de Lyon, Villeurbanne

13. Collet F, Prétot S (2014) Thermal conductivity of hemp concretes: variation with formulation, density and water content. Constr Build Mater 65:612-619

14. Balčiūnas G et al (2013) Physical properties and structure of composite made by using hemp hurds and different binding materials. Procedia Eng 57:159-166

15. Elfordy S et al (2008) Mechanical and thermal properties of lime and hemp concrete ("hempcrete") manufactured by a projection process. Constr Build Mater 22(10):2116-2123

16. Tronet $\mathrm{P}$ et al (2016) Study of lime hemp concrete (LHC) mix design, casting process and mechanical behaviour. Cem Concr Compos 67:60-72

17. Hirst EAJ (2013) Characterisation of hemp-lime as a composite building material. University of Bath, Bath 
18. Magniont $\mathrm{C}$ et al (2012) Use of plant aggregates in building ecomaterials. Eur J Environ Civil Eng 16(sup1):s17-s33

19. Gross C et al. (2012) Structural enhancement of timber stud framing using renewable insulation materials. In: 12th world conference on timber engineering, p 19

20. Pierre T, Colinart T, Glouannec P (2014) Measurement of thermal properties of biosourced building materials. Int $\mathrm{J}$ Thermophys 35(9-10): 1832-1852

21. Nozahic V et al (2012) Design of green concrete made of plant-derived aggregates and a pumice-lime binder. Cem Concr Compos 34(2):231-241

22. Bevan R et al (2008) Hemp Lime Construction: a guide to building with hemp lime composites. BRE Press, Berkshire

23. Lanos $C$ et al (2013) Formulation and implementation. In: Arnaud L, Amziane S (eds) Bio-aggregate-based building materials. Wiley, New York, pp 117-152

24. British Standards (2013) BS EN 826:2013-thermal insulating products for building applications. Determination of compression behaviour. Wärmedämmstoffe für das Bauwesen. Bestimmung des Verhaltens bei Druckbeanspruchung

25. British Standards (2009) BS EN 12390-3:2009-testing hardened concrete. Compressive strength of test specimen
26. Sinka M, Sahmenko G (2013) Sustainable thermal insulation biocomposites from locally available hemp and lime. Environ Technol Resour 1:73-77

27. Sassoni E et al (2014) Novel sustainable hemp-based composites for application in the building industry: physi$\mathrm{cal}$, thermal and mechanical characterization. Energy Build 77:219-226

28. Youssef A et al. (2015) Compressive and shearing behaviour of lime and hemp concrete. In: First international conference on bio-based biulding materials, Clermont-Ferrand, France

29. Amziane S, Nozahic V, Sonebi M (2015) Design of mechanically enhanced concrete using hemp shiv. In: First international conference on bio-based building materials, Clermont-Ferrand, France

30. Dinh T et al. (2015) Hemp concrete using innovative pozzolanic binder. In: First international conference on biobased building materials, Clermont-Ferrand, France

31. Kutay ME et al (2010) Three-dimensional image processing methods to identify and characterise aggregates in compacted asphalt mixtures. Int J Pavement Eng 11(6):511-528

32. Hankinson R (1921) Investigation of crushing strength of spruce at varying angles of grain. Air Serv Inf Circ 3(259): 130 